\title{
Pulmonary vascular resistance during lipid infusion in neonates
}

\author{
W Prasertsom, E Z Phillipos, J E Van Aerde, M Robertson
}

\begin{abstract}
Using two-dimensional echocardiography, pulmonary vascular resistance was estimated from right ventricular pre-ejection period to ejection time (RVPEP/ET) in 11 preterm infants with respiratory distress, to test the effect of different doses of continuous lipid infusion. Echocardiography was performed at baseline with no lipid infusing 2 and 24 hours after 1.5 and 3 g/kg/day of intravenous lipid, 24 hours after discontinuing intravenous lipid emulsion, and 2 hours after restarting intravenous lipid. After 24 hours of intravenous lipid at $1.5 \mathrm{~g} / \mathrm{kg} /$ day the RVPEP/ET rose to mean (SD) $0.287(0.03)$ from a baseline value of $0.225(0.02)$ and to 0.326 $(0.05)$ after 24 hours of intravenous lipid at $3 \mathrm{~g} / \mathrm{kg} / \mathrm{day}$. Pulmonary arterial pressure returned to baseline 24 hours after the intravenous lipid had been discontinued. Continuous 24 hour infusion of lipid caused significant dose and time-dependent increases in pulmonary vascular resistance. Intravenous lipid may aggravate pulmonary hypertension.

(Arch Dis Child 1996; 74: F95-F98)
\end{abstract}

Keywords: total parenteral nutrition, lipid emulsion, pulmonary vascular resistance, echocardiography, respiratory distress.

The use of intravenous lipid emulsions as part of total parenteral nutrition (TPN) is standard practice in the care of preterm infants. In many newborn and adult species the short term and long term complications associated with intravenous lipid emulsions include decreased arterial oxygen tensions ${ }^{1}$ and pulmonary diffusing capacity, ${ }^{2}$ increased pulmonary vasomotor tone, and arterial pressure. ${ }^{3-6}$ In the human neonate there have been reports of histological evidence of pulmonary hypertension and pulmonary arterial lipid deposit ${ }^{7-9}$; and chronic lung disease. ${ }^{1011}$ The alteration in the pulmonary vasomotor tone caused by intravenous lipid may be mediated by alterations in eicosanoid metabolism. ${ }^{10-14}$ In lambs intravenous soybean oil emulsions cause an acute dose-dependent increase in pulmonary arterial pressure, a modest decrease in arterial oxygen tension, and a significant increase in thromboxane $\mathrm{A}_{2} \cdot{ }^{12}$ In low birthweight (LBW) infants without respiratory distress pulmonary arterial diastolic pressure (PADP), as estimated from the right ventricular pre-ejection period over ejection time (RVPEP/ET), increased during the infusion of $0.2-0.9 \mathrm{~g} / \mathrm{kg}$ of intravenous lipid over 2 hours $^{15}$ which is equivalent to
$2 \cdot 4-10 \cdot 8 \mathrm{~g} / \mathrm{kg} / \mathrm{day}$. Not only is this dose higher than the recommended amount of intravenous lipid - up to $3 \mathrm{~g} / \mathrm{kg} /$ day $^{16}$ - but it is also well known that clearance of lipid particles is a function of the amount of emulsion administered over a given time. ${ }^{17}$ PADP estimates have not been reported in infants with respiratory distress and receiving 24 hour lipid infusions as part of TPN rather than as short term high dose infusions.

The objective of this study was to investigate the effect of different doses of intravenous lipid within the range of current practice for TPN and administered as a continuous infusion, on the pulmonary vascular resistance of LBW infants with different degrees of neonatal respiratory distress, as estimated from RVPEP/ET using two-dimensional and Doppler echocardiography. We hypothesised: (1) that infusion of any amount of intravenous lipid results in an increase in PADP in LBW infants compared with pre-infusion values; and (2) that increasing the amount of intravenous lipid results in higher pulmonary arterial pressure in LBW infants.

\section{Methods}

Infants were selected with a birthweight of less than $2000 \mathrm{~g}$ and appropriate for gestational age, who required respiratory support such as intermittent mandatory ventilation, continuous positive airway pressure, or oxygen hood for different degrees of respiratory distress. Respiratory distress was diagnosed if the infant developed respiratory difficulties requiring oxygen and/or positive pressure ventilation, with the typical chest radiograph appearance of hyaline membrane disease. The infants were excluded from the study if there was echocardiographic evidence of cardiovascular disease except for patent ductus arteriosus (PDA), if the infant was clinically too unstable to be examined echocardiographically, if indomethacin or steroids had been given, if there was fluid restriction (more than $20 \%$ below standard volume), or if surfactant had been given within 4 hours of echocardiographic study.

A $20 \%$ lipid emulsion (Intralipid, Kabi Pharmacia, Quebec, Canada) was started on the second day of life, between 24 and 48 hours postnatally, as part of standard TPN. A dose of $0.0625 \mathrm{~g} / \mathrm{kg} /$ hour was given for 24 hours $(1.5 \mathrm{~g} / \mathrm{kg} /$ day) and increased to 0.125 $\mathrm{g} / \mathrm{kg} /$ hour for another 24 hours ( $3 \mathrm{~g} / \mathrm{kg} /$ day) on the third day. On the fourth day of life intravenous lipid was discontinued for 24 hours, after which time a dose of $0.0625 \mathrm{~g} / \mathrm{kg} /$ hour $(1.5 \mathrm{~g} / \mathrm{kg} /$ day $)$ was restarted. Fat overload was
Dr J Van Aerde

Accepted 9 October 1995 
avoided by checking to see that the serum triglycerides were below $1 \mathrm{mmol} / \mathrm{h}, 17 \quad 18 \quad 24$ hours after any change in lipid infusion rate.

Seven two-dimensional echocardiograms were performed in the following sequence: (1) before intravenous lipid infusion on the second day of life; (2) 2 hours after initiation of $0.0625 \mathrm{~g} / \mathrm{kg} / \mathrm{hour}(1.5 \mathrm{~g} / \mathrm{kg} /$ day $)$ of intravenous lipid infusion; (3) 24 hours after starting $0.0625 \mathrm{~g} / \mathrm{kg} /$ hour $(1.5 \mathrm{~g} / \mathrm{kg} /$ day $)$ of intravenous infusion on the third day of life; (4) 2 hours after increasing to $0.125 \mathrm{~g} / \mathrm{kg} /$ hour ( $3 \mathrm{~g} / \mathrm{kg} /$ day) of intravenous lipid infusion on the third day of life; (5) 24 hours after increasing to 0.125 $\mathrm{g} / \mathrm{kg} /$ hour ( $3 \mathrm{~g} / \mathrm{kg} /$ day) of intravenous lipid infusion on the fourth day of life; (6) 24 hours after intravenous lipid was discontinued on the fifth day of life; and (7) 2 hours after 0.0625 $\mathrm{g} / \mathrm{kg} /$ hour $(1.5 \mathrm{~g} / \mathrm{kg} /$ day $)$ of intravenous lipid had been restarted.

The echocardiograms were done using an Ultramark 4 with a $5 \mathrm{MHz}$ mechanical sector transducer. The investigator reading the echocardiogram was blinded to the treatment status; intra-observer error was $\langle \pm 8 \%$ of mean $( \pm 2 \mathrm{SD})$. A different investigator who performed the echocardiogram was not blinded to the treatment status. The Doppler flow velocity across the aortic and pulmonary valve and simultaneous ECG were recorded, and the left ventricular pre-ejection period over ejection time (LVPEP/ET) and RVPEP/ET were measured. Six readings were performed for each value to reduce the measurement error. RVPEP/ET was used to estimate PADP echographically because it is independent of heart rate. ${ }^{19}$ Pre-ejection periods were measured from onset of the $Q$ wave of a simultaneously recorded ECG tracing to onset of flow. The duration of flow was measured as ejection time. $^{20}$

For the ventilated infants, the ventilatory settings were adjusted to maintain the $\mathrm{pH}$ between 7.30 and $7 \cdot 40$, the arterial carbon dioxide tension $\left(\mathrm{PaCO}_{2}\right)$ between 35 and 50 $\mathrm{mm} \mathrm{Hg}$. The mean airway pressure was maintained at the same level during the two hour interval between the first and the second echocardiogram on each day, to avoid an effect of changing mean airway pressure on PADP.

Written informed consent was obtained from one of the parents before including the infant in the study. The studies were approved by the Ethics Review Committee of the University of Alberta Hospitals and the Faculty of Medicine of the University of Alberta.

Each infant served as its own control. Values are expressed as mean (SD). RVPEP/ET and LVPEP/ET measured at different times during
Table 1 Patients and fluid intake

\begin{tabular}{lccc}
\hline Patient data $(n=11)$ & Mean $(S D)$ & Median & Range \\
\hline Birthweight (g) & $1280(218)$ & 1345 & $904-1625$ \\
Gestational age (weeks) & $29 \cdot 3(1 \cdot 1)$ & 29 & $28-31$ \\
Total fluid intake (ml/kg/day) & & \\
Day 2 & $110(21)$ & 106 & $90-165$ \\
Day 3 & $133(24)$ & 129 & $93-170$ \\
Day 4 & $141(23)$ & 146 & $100-176$ \\
Day 5 & $145(25)$ & 150 & $113-203$ \\
\hline
\end{tabular}

infusion of different amounts of intravenous lipid were evaluated using Friedman Repeated Measures Analysis of Variance on Ranks, corrected by the Student-Newman-Keuls test. (Sigmastat, Jandel Scientific, San Raphael, California). A P value of $<0.05$ was accepted as significantly different.

\section{Results}

A total of 14 preterm infants, born between 15 March and 1 June 1994, with a birthweight of less than $2000 \mathrm{~g}$, who developed respiratory distress and received TPN, were studied in the neonatal intensive care unit at the University of Alberta Hospital. Three of them were excluded from the study because they had been given indomethacin. Eleven infants completed the series of echocardiograms. The mean (SD) gestational age was $29.4(1 \cdot 1)$ weeks (median 29; range 28-31 weeks) and mean birthweight 1280 (218) g (median $1345 \mathrm{~g}$; range 904-1625 g). The male:female ratio was 6:5 (table 1 ). Total fluid intake was 110 (21) $\mathrm{ml} / \mathrm{kg} /$ day on the second day of life, 133 (24) $\mathrm{ml} / \mathrm{kg} /$ day on the third day, 141 (23) $\mathrm{ml} / \mathrm{kg} /$ day on the fourth day and $145(25) \mathrm{ml} / \mathrm{kg} /$ day on the fifth day of life (table 1). Serum triglyceride concentrations were below $1 \mathrm{mmol} / \mathrm{l}$ during the entire study. Of the 11 infants, 10 developed respiratory distress which required mechanical ventilation and one infant developed mild respiratory distress and needed oxygen in a hood. Four infants who had an arterial:alveolar oxygen ratio of less than 0.22 received surfactant replacement therapy within 12 hours of age. All infants had their first echocardiogram performed at least 12 hours after surfactant replacement or diuretic therapy. The mean airway pressure was maintained at the same level during the two hour interval between the first and second echocardiogram on the second day of life, between the third and fourth echocardiogram on the third day of life, and between the sixth and seventh echocardiogram on the fifth day of life. Of 10 infants who required ventilatory assistance, two were extubated before the first echocardiogram, three more before the third echocardiogram, two more before the fifth echocardiogram, one

Table 2 RVPEP/ET and LVPEP/ET

\begin{tabular}{|c|c|c|c|c|c|c|c|}
\hline $\begin{array}{l}\text { Day of life } \\
\text { Time(hours) } \\
\text { Dose } \\
\text { RVPEP/ET } \\
\text { LVPEP/ET } \\
\text { Infants intubated } \\
\text { MAP } \\
\text { Range }\end{array}$ & $\begin{array}{l}2 \\
\text { Baseline } \\
0 \\
0 \cdot 225(0.02)^{\mathrm{a}} \\
0 \cdot 235(0.02) \\
8 \\
5 \cdot 4(1) \\
4-7\end{array}$ & $\begin{array}{l}2 \\
0 \cdot 247(0.03)^{\mathrm{a}} \\
0 \cdot 244(0.01) \\
8 \\
5 \cdot 4(1) \\
4-7\end{array}$ & $\begin{array}{l}3 \\
24 \\
y \\
0 \cdot 287(0.03)^{b} \\
0 \cdot 244(0.02) \\
5 \\
6(1 \cdot 2) \\
5-8\end{array}$ & $\begin{array}{l}2 \\
0.289(0.04)^{\mathrm{b}} \\
0 \cdot 26(0 \cdot 02) \\
5 \\
6(1 \cdot 2) \\
5-8\end{array}$ & $\begin{array}{l}4 \\
24 \\
y \\
0.326(0.05)^{c} \\
0.255(0.02) \\
3 \\
5.3(0.5) \\
5-6\end{array}$ & $\begin{array}{l}5 \\
\text { Stop } 24 \\
0 \\
0 \cdot 246(0 \cdot 04)^{\mathrm{a}} \\
0 \cdot 255(0 \cdot 02) \\
2 \\
6(1) \\
5-7\end{array}$ & $\begin{array}{l}2 \\
1.5 \mathrm{~g} / \mathrm{kg} / \mathrm{day} \\
0 \cdot 255(0.03)^{\mathrm{a}} \\
0 \cdot 25(0.03) \\
2 \\
6(1) \\
5-7\end{array}$ \\
\hline
\end{tabular}

Numbers with different superscript are significantly different $(P<0.05)$; mean $\pm(S D)$. MAP: mean airway pressure in $\mathrm{cm} \mathrm{H}_{2} \mathrm{O}$. 


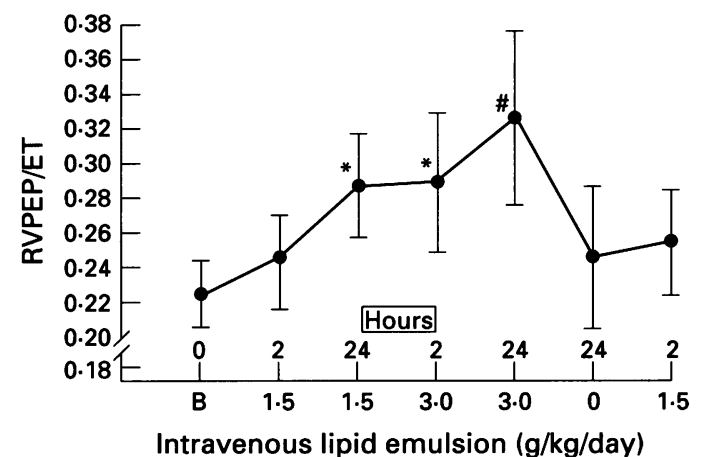

Right ventricular pre-ejection period to ejection time (RVPEP/ET) measured at baseline (B), 2, and 24 hours after starting $1.5 \mathrm{~g} / \mathrm{kg} /$ day of intravenous (IV) lipid; 2 and 24 hours after $3 \mathrm{~g} / \mathrm{kg} /$ day of IV lipid; 24 hours after discontinuing IV lipid; and 2 hours after restarting lipid infusion at $1.5 \mathrm{~g} / \mathrm{kg} /$ day. The data points $(X \pm S D)$ with different symbols are significantly different $(P<0 \cdot 05)$.

before the sixth echocardiogram (table 2), and two remained intubated until after the seventh echocardiogram (table 2 ). The maximum mean airway pressure during the study period was 8 $\mathrm{cm} \mathrm{H}_{2} 0$. Six of the infants required nasal continuous positive pressure after extubation.

RVPEP/ET increased significantly from $0.225(0.02)$ at baseline to $0.287(0.03)$ after 24 hours of intravenous lipid at $1.5 \mathrm{~g} / \mathrm{kg} /$ day $(P<0 \cdot 05)$. RVPEP/ET further increased significantly to $0.326(0.05)$ after 24 hours of intravenous lipid at a dose of $3 \mathrm{~g} / \mathrm{kg} / \mathrm{day}$ $(P<0 \cdot 05)$ (figure, table 2). Twenty four hours after intravenous lipid had been discontinued, RVPEP/ET dropped to $0 \cdot 246(0.04)$, similar to baseline level and significantly lower than the RVPEP/ET value during both levels of lipid infusion (figure, table 2). All the RVPEP/ET values after 2 hours of starting, restarting, or increasing the lipid dose were not significantly different from the values before the changes. The changes in RVPEP/ET for dose and time were similar for each of the 11 infants. An RVPEP/ET value greater than 0.28 has been previously used to indicate pulmonary hypertension. ${ }^{15}$ In five of the 11 infants RVPEP/ET rose to $>0.28$ (range $0.298-0.365$ ) after 24 hours of intravenous lipid at $1.5 \mathrm{~g} / \mathrm{kg} /$ day. In all but one, RVPEP/ET rose to $>0 \cdot 280$ (range $0 \cdot 241-0.438$ ) after 24 hours of intravenous lipid at $3 \mathrm{~g} / \mathrm{kg} /$ day. There was no significant change in LVPEP/ET (table 2).

To ensure that these findings were not a naturally occurring phenomenon, we performed five serial echocardiograms in each of eight healthy preterm infants who did not have any degree of lung disease and who were not receiving intravenous lipid. There was no significant change in RVPEP/ET or LVPEP/ET values which remained similar for each of the infants. RVPEP/ET values in the control group were $0.256(0.02), 0.248(0.02)$, $0.235(0.03)$, and $0.226(0.02)$ for the first four echocardiograms, and all values were $<0 \cdot 28$.

\section{Discussion}

The early administration of intravenous lipid emulsions to premature infants has been associated with the development of pulmonary and circulatory complications. ${ }^{17-11} 15$ Our data suggest that a continuous 24 hour infusion of intravenous lipid as part of TPN causes a significant dose and time-dependent increase in pulmonary vascular resistance in preterm infants with respiratory distress. By comparison, systemic vascular resistance, as estimated by LVPEP/ET, is unaffected by infusion of lipid. Discontinuing the lipid infusion results in RVPEP/ET values returning to pre-infusion figures. Our findings were consistent in each of the 11 infants.

RVPEP/ET measured by two-dimensional echocardiography is a non-invasive assessment of the pulmonary vascular haemodynamics and a good correlation with PADP has been shown by cardiac catheterisation. ${ }^{19-21}$ RVPEP/ET is not influenced by either age or heart rate, ${ }^{18}$ but it is affected by right ventricular preload and function. ${ }^{15}$ Right ventricular preload, estimated from RVED, did not change during these studies. Each infant in our study served as its own control, and intraventricular conduction was therefore not a source of variance. Consequently, measuring RVPEP/ET serially in the same infant has been considered valuable in detecting trends and changes in PADP. ${ }^{22-24}$ Although pulmonary arterial pressure can be assessed more accurately by using the Doppler calculated pressure gradient between aorta and main pulmonary artery, only two of the 11 infants studied had a patent ductus arteriosus for the duration of the study. In all infants the velocity profile across the patent ductus arteriosus was left to right by day 2 of age.

Lloyd et al have reported an increase in RVPEP/ET in preterm infants without lung disease when infusing 0.2 to $0.9 \mathrm{~g} / \mathrm{kg}$ of lipid over 2 hours. ${ }^{15}$ This is equivalent to $2 \cdot 4-10 \cdot 8$ $\mathrm{g} / \mathrm{kg}$ of intravenous lipid a day, much higher than the $1.5 \mathrm{~g}$ and $3 \mathrm{~g} / \mathrm{kg} /$ day in our study. This large difference in the amount administered might explain why Lloyd et $a l^{15}$ did, and why we did not, find a significant increase in RVPEP/ET after 2 hours. Whereas $1.5 \mathrm{~g}$ and 3 $\mathrm{g} / \mathrm{kg} /$ day of intravenous lipid may be too low to cause mechanical ${ }^{79}$ or immediate thromboxane-induced pulmonary vasoconstriction, ${ }^{11-13}$ the higher doses given by Lloyd et al might have been high enough, particularly as they found a weak correlation between lipid dose and change in RVPEP/ET. ${ }^{15}$

Lloyd et al arbitrarily chose a RVPEP/ET value of $>0.28$ to indicate pulmonary hypertension, with less than $50 \%$ of the infants studied reaching RVPEP/ET values greater than $0 \cdot 280 . .^{15}$ After 24 hours of intravenous lipid, at both doses of 1.5 and $3 \mathrm{~g} / \mathrm{kg} /$ day, we found a significant increase in RVPEP/ET, with values greater than 0.280 in 10 out of 11 infants at a dose of $3 \mathrm{~g} / \mathrm{kg} /$ day. In our group the highest RVPEP/ET $(0.326 \quad(0.05))$ was reached on day 4 of life, 24 hours after starting $3 \mathrm{~g} / \mathrm{kg} /$ day of intravenous lipid. This cannot be explained by worsening lung disease because eight of the 11 infants no longer required assisted ventilation at that time. Furthermore, on day 5, when intravenous lipid had been stopped for 24 hours, RVPEP/ET values 
returned to baseline. During the study period, medication which, theoretically, could have had an effect on PADP, such as diuretics, surfactant, indomethacin and steroids, was not administered between 24 and 120 hours of life as it would have meant excluding that infant from the study.

The fact that changes in RVPEP/ET occurred 24 hours and not 2 hours after changing the dose of intravenous lipid might have been caused by changes in eicosanoid metabolism, rather than a mechanical obstructive effect. Some studies have associated the increase in PADP with hyperlipidemia ${ }^{2}$ but none of our infants was hyperlipaemic. It is more likely that the dose-dependent increase in pulmonary arterial pressure is thromboxane mediated. In lambs intravenous soybean oil emulsions have been reported to cause an acute dose-dependent increase in pulmonary arterial pressure with no significant change in cardiac output or left atrial pressure. ${ }^{12}$ This effect has been modified by the administration of indomethacin. ${ }^{25}$ In newborn piglets the link between intravenous soybean oilinduced pulmonary hypertension and thromboxane $A_{2}$ has been reinforced by blocking the vasoconstrictive reaction with specific thromboxane antagonists. ${ }^{13}$ Evidence indicates that leukotrienes may also have a major role in pulmonary hypertension. ${ }^{26-29}$ Whether their production increases during infusion of a soybean oil emulsion has not been investigated. Some evidence on thromboxane related pulmonary hypertension induced by intravenous soybean oil emulsions in newborn infants has also been provided. ${ }^{10}$

On the one hand, intravenous lipid should be started on the first day of life to maintain a positive energy balance in infants weighing less than $1500 \mathrm{~g}$ at birth. ${ }^{30}$ Furthermore, all our infants improved clinically despite the increases in RVPEP/ET. On the other hand, our findings give some cause for concern, as infants with more severe respiratory distress with evidence of increased pulmonary vascular resistance might deteriorate clinically. Administering antagonists of specific eicosanoid metabolites or changing the precursor in the intravenous lipid emulsion might alter the dose-dependent increases in RVPEP/ET induced by intravenous lipid.

Supported by a grant from the Medical Research Council of Canada.

We thank George Chan for technical assistance and Judy Minckler for secretarial support.

1 Pereira GR, Fox WW, Stanley CA. Decreased oxygenation and hyperlipidemia during intravenous fat infusion in and hyperlipidemia during intravenous fat

2 Greene HL, Hazlett D, Demarce R. Relationship between intralipid-induced hyperlipemia and pulmonary function. Am $\mathcal{F}$ Clin Nutr 1976; 29: 127-35.
3 McKeen CR, Brigham KL, Bowers RE. Pulmonary vascular effects of fat emulsion infusion in unanesthetized sheep. f Clin Invest 1978; 61 : 1291-7.

4 Inwood RJ, Gora P, Hunt C. Indomethacin inhibition of intralipid-induced lung dysfunction. Prostaglandins Med 1981; 6: 503-14.

5 Hageman JR, McCullock K, Gora P, Olsen EK. Intralipid alterations in pulmonary prostaglandin metabolism and gas exchange. Crit Care Med 1983; 11: 794-8.

6 Kjave JC, Dahl PE. Pulmonary hypertension and microvascular injury in rats given parenteral nutrition. Acta Chi Scand 1989; 155: 439-43.

7 Dahms BB, Halpin TC. Pulmonary arterial lipid deposit in newborn infants receiving intravenous lipid infusion. f Pediatr 1980; 97: 800-5.

8 Shulman RJ, Langston C, Schanler RJ. Pulmonary vascular lipid deposition after administration of intravenous fat to infants. Pediatrics 1987; 79: 99-102.

9 Levene MI, Wigglesworth JS, Desai R. Pulmonary fat accumulation after intralipid infusion in the preterm infant Lancet 1980; ii: 815-8.

10 Hammerman C, Aramburo MJ. Decreased lipid intake reduces morbidity in sick premature neonates. $\mathcal{F}$ Pediatr 1988; 113: 1083-8.

11 Cooke RWI. Factors associated with chronic lung disease in preterm infants. Arch Dis Child 1991; 66: 776-9.

12 Teague WG, Raj JU, Braun D, Berner ME. Lung vascular effects of lipid infusion in awake lambs. Ped Res 1987; 22: 714-19.

13 Hammerman C, Aramburo MJ, Hill V. Intravenous lipids in newborn lungs: Thromboxane-mediated effects. Cri Care Med 1989; 17: 430-6.

14 Gurtner GH, Knoblauch A, Smith PL. Oxidant- and lipidinduced pulmonary vasoconstriction mediated by arachidonic acid metabolites. F Appl Physiol 1983; 55: 949-54.

15 Lloyd TR, Boucek MM. Effect of intralipid on the neonatal pulmonary bed: An echographic study. $\mathcal{F}$ Pediatr 1986 108: $130-3$.

16 Heird WC, Gomez MR. Parenteral Nutrition. In: Tsang R Lucas A, Uavy R, Zlotkin S, eds. Nutritional needs of the preterm infant. Baltimore: Williams \& Wilkins, 1993: 225-42.

17 Brans YW, Andrew DS, Carrillo DW. Tolerance of fat emulsions in very-low-birth-weight neonates. $A m \mathcal{F} D$ is Child 1988; 142: 145-52.

18 Dhanireddy $R$, Hamosh $M$, Sivasubramanian $K N$ Postheparin lipolytic activity and intralipid clearance in very low-birthweight infants. $\mathcal{F}$ Pediatr 1981; 98: 617-22.

19 Hirschfeld S, Meyer R, Schwart DC, Korfhagen UT, Kaplan S. The echocardiographic assessment of pulmonary artery pressure and pulmonary vascular resistance. Circulation 1975; 52: 642-50.

20 Senecal F, Weyman AE, Pyhel HJ. Estimation of pulmonary artery pressure by pulsed Doppler echocardiography. Circulation 1977; 56: III-25.

21 Foult JM, Blanchard D, Bonan R, Bourassa MG, Water D. Noninvasive measurement of pulmonary artery pressure using pulsed Doppler echocardiography. Circulation 1980; 62: III-99.

22 Riggs T, Hirschfeld S, Fanaroff A, Liebman J. Persistence of fetal circulation: an echographic study. $\mathcal{F}$ Pediatr 1977 91: 626-31.

23 Fouron JC, Le Guennect JC, Villemant D, Bard $H$ Perreault G, Davignon A. Value of echocardiography in assessing the outcome of bronchopulmonary dysplasia of the newborn. Pediatrics 1980; 65: 529-35.

24 Nussbaum E, Hirschfeld SS, Wood RE, Boat TF, Doershuk CF. Echocardiographic changes in children with pulmonary hypertension secondary to upper airway obstruction. F Pediatr 1978; 93: 931-6.

25 Inwood R, Gora P, Hunt C. Indomethacin inhibition of Intralipid-induced lung dysfunction. Prostaglandins Med 1981; 6: 503-14.

26 Scott T, Soifer J, Schreiber MD, Heymann MA, Hellgath MC. Leukotrienes mediate thromboxane- mimetic induced pulmonary vasoconstriction in newborn lambs. Ped Res 1987; 21: 466A.

27 Taylor B. Leukotriene antagonist FPL 55712 reverses hypoxic pulmonary vasoconstriction in piglets. Ped Res 1988; 23: 527A.

28 Ahmed T, Marchette B, Wanner A. Direct and indirect effects of leukotriene D4 on the pulmonary and systemic circulations. Am Rev Respir Dis 1985; 131: 554-8.

29 Coe J, Olley P, Coceani F. The effect of leukotriene D4 on pulmonary and systemic circulation in conscious newborn puiglets. Prostaglandins 1988; 36: 31-47.

30 Gilbertson N, Kovar LZ, Vox DI. Introduction of intravenous lipid administration on the first day of life in the very low birth weight neonate. $\mathcal{F}$ Pediatr 1991; 119: 615-23. 